\title{
PENGARUH KEBERADAAN OBJEK MANUSIA TERHADAP STABILITAS RECEIVED SIGNAL STRENGTH INDICATOR (RSSI) PADA BLUETOOTH LOW ENERGY 4.0 (BLE)
}

\author{
Budy Santoso ${ }^{1}$, Lukito Edi Nugroho ${ }^{2}$, Hanung Adi Nugroho ${ }^{3}$ \\ ${ }_{1,2,3)}$ Jurusan Teknik Elektro dan Teknologi Informasi \\ Universitas Gadjah Mada \\ Jl. Grafika No.2 Yogyakarta - 55281
}

Email : budy.santoso.mti13@mail.ugm.ac.id, lukito@ugm.ac.id, adinugroho@ugm.ac.id'

\begin{abstract}
There are many systems with diverse technologies such as GPS, Wi-Fi, Bluetooth, Zigbee, Ultra Wide Band, Ultrasound, Infrared can be used for location-based services. Of these technologies can be developed several applications for positioning purposes such as monitoring patients in hospitals or elderly people who are undergoing treatment at home. This paper proposes a simple method to estimate the presence of the object / user in a fixed area using parameter Received Signal Strength Indicator (RSSI) on Bluetooth 4.0 Low Energy (BLE). To determine the performance of the RSSI, conducted two experiments in a room scenario dimensions $3 x$ $2.80 \times 2.5 \mathrm{~m}$ (present and not present). Two experiments were conducted to test the performance of the RSSI signal. The first experiments with conditions not present showed a good performance. However, in the second experiment (present) with the status of various objects that are in the same room, resulting in poor performance of RSSI, where there is a shift in the RSSI value at the first measurement was obtained average RSSI -73 dBm with a range distance of $2 \mathrm{~m}$, the second measurement obtained an average RSSI value of $-85 \mathrm{dBm}$ at a distance of $3 \mathrm{~m}$ range. With these results it can be concluded that the human presence in the area of research is very influential on the performance positioning signal strength (RSSI) and the significant impact that the shift distance of up to $1 \mathrm{~m}$.
\end{abstract}

Keywords: Bluetooth Low Energy, RSSI, indoor positioning

\section{Abstrak}

Terdapat banyak system dengan bermacam-macam teknologi seperti GPS, Wi-Fi, Bluetooth, Zigbee, Ultra Wide Band, Ultrasound, Infrared yang dapat digunakan untuk layanan berbasis lokasi. Dari teknologi tersebut dapat dikembangkan beberapa aplikasi untuk keperluan positioning seperti pemantauan pasien di rumah sakit atau manula yang sedang menjalani treatment di rumah. Makalah ini mengusulkan sebuah metode sederhana untuk memperkirakan keberadaan objek/pengguna pada sebuah fixed area menggunakan parameter Received Signal Strength Indicator (RSSI) pada Bluetooth Low Energy 4.0 (BLE). Untuk mengetahui unjuk kerja $R S S I$, dilakukan dua skenario percobaan pada sebuah ruangan berdimensi $3 \times 2.80 \times 2.5 \mathrm{~m}$ (present dan not present). Terdapat dua percobaan yang dilakukan untuk menguji kinerja sinyal RSSI. Percobaan pertama dengan kondisi not present menunjukkan kinerja yang baik. Namun, pada percobaan kedua (present) dengan berbagai status objek yang berada di ruangan yang sama, menghasilkan kinerja RSSI yang kurang baik, dimana terdapat pergeseran nilai RSSI pada pengukuran pertama diperoleh rata-rata $R S S I-73 \mathrm{dBm}$ dengan range jarak $2 \mathrm{~m}$, pengukuran kedua diperoleh nilai rata-rata $R S S I-85 \mathrm{dBm}$ dengan range jarak $3 \mathrm{~m}$. Dengan hasil tersebut diatas dapat disimpulkan bahwa human presence dalam area penelitian positioning sangat berpengaruh terhadap kinerja kuat sinyal (RSSI) dan memberikan dampak yang signifikan yaitu pergeseran jarak hingga $1 \mathrm{~m}$.

Kata kunci: Bluetooth Low Energy, RSSI, indoor positioning 


\section{PENDAHULUAN}

Dewasa ini, layanan berbasis lokasi (Location Based Sevices/LBS) telah banyak diaplikasikan dalam berbagai area, aplikasi pelacakan dan piranti bergerak dimana kemampuan mengenali lokasi objek menjadi bagian penting dalam kehidupan sehari-hari (Nuaimi \& Kamel, 2011). Sebagaimana diketahui bahwa, para peneliti membagi LBS menjadi dua yaitu pemosisian luar ruangan (outdoor positioning) dan pemosisian dalam ruangan (indoor positioning). Dengan pertumbuhan infrastruktur bangunan, tower dan fasilitas umum lainnya tentunya teknologi outdoor positioning tidak tepat digunakan untuk LBS.

Menurut hasil penelitian (indoor, 2010) $70 \%$ orang menghabiskan waktunya di dalam ruangan, mengindikasikan pentingnya pemanfaatan LBS. Meskipun outdoor positioning telah mengalami perkembangan yang lebih luas dalam penelitian dan aplikasi, indoor positioning saat ini memiliki tantangan dari segi teknis dan metodenya. Sebagai contoh, GPS tidak bekerja dengan baik didalam ruangan karena banyaknya propagasi. Teknik indoor positioning umumnya memanfaatkan frekuensi radio seperti Wi-Fi, ZigBee, RFID dan Bluetooth Low Energy (BLE).

BLE merupakan spesifikasi terbaru dari Bluetooth, keuntungan dari BLE ini adalah memiliki konsumsi energi yang rendah, dapat menggunakan baterai dan banyak digunakan untuk aplikasi smart home, kesehatan dan fitnes (SIG, 2014). Disisi lain, memungkinkan penyebaran sinyal dengan cepat dan dapat menggantikan infrastruktur Wi-Fi yang bergantung dengan daya listrik.

Beberapa study tentang penggunaan RSSI untuk keperluan indoor positioning telah banyak dipublikasikan. Pada referensi (Liu, 2007; Pirzada etal, 2013; Jornal \& Engineering, 2013; Yan etal, 2013) membahas tentang perbandingan dari sistem penentuan lokasi dengan menggunakan UWB, RSSI, GPS, Bluetooth, WLAN, GSM/CDMA, RFID. Beberapa algoritma estimasi posisi diklasifikasikan menjadi empat kategori : triangulation, fingerprinting, proximity dan vision analysis (Liu etal, 2007; Rida etal, 2015).

Saat ini, teknik radio frequency (RF) sangat umum digunakan untuk indoor positioning karena kebutuhan hardware lebih rendah daripada dengan metode pendekatan lain, dan memiliki estimasi error lebih rendah dibandingkan dengan menggunakan GPS dan GSM/CDMA.

Umumnya penelitian sebelumnya yang menggunakan teknik RF untuk indoor positioning bertujuan untuk mengestimasi koordinat/posisi dari objek/pengguna. Namun pada makalah ini bertujuan untuk mengetahui keberadaan objek/pengguna (present or not present) pada sebuah fixed area yang telah ditentukan dengan menggunakan BLE yang dipasang pada ruangan.

\section{Gambaran Sistem}

Pada makalah ini, penulis mengusulkan sebuah teknik untuk mengetahui keberadaan objek/pengguna pada sebuah path antara transmitter $(T x)$ dan receiver $(R x)$ pada BLE yang dipasang didalam ruangan berukuran $3 \times 2,80 \times 2,5 \mathrm{~m}$ dengan menggunakan nilai RSSI pada BLE. Konfigurasi dasar transmitter dan receiver seperti pada gambar 1(a), dimana terdiri dari $T X$ dan $R x$. Masing-masing Tx memiliki satu sensor untuk mengcapture sinyal Bluetooth dari Rx informasi ruang uji, dalam hal ini $\mathrm{Rx}$ adalah smartphone yang memiliki fitur BLE 4.0. Sinyal RF (path antara Tx dan Rx) pada dasarnya stabil jika tidak ada yang menggangu (obstacles). Namun dengan keberadaan objek pada path tersebut mengganggu sinyal RF sehingga kekuatan sinyal (Signal Strength) bervariasi pada saat uji coba (gambar 1(b)). Sistem dapat mengenali keberadaan objek pada path jika sinyal melebihi threshold. Process unit merupakan software pihak ketiga yang sengaja dipasang pada smarthphone pada proses pengukuran untuk mengcapture nilai RSSI pada beacon. 


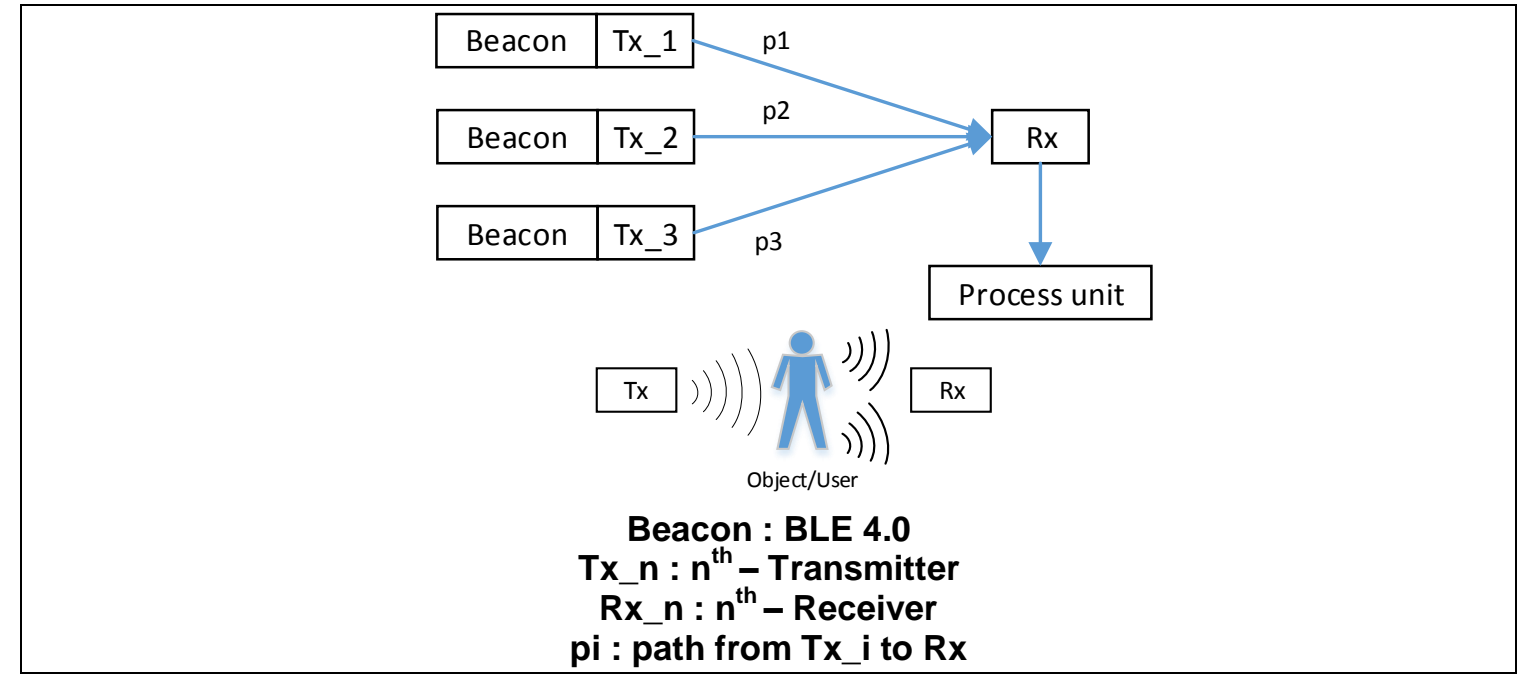

Gambar 1. (a) Konfigurasi dasar sistem yang diusulkan;(b) signal path RF yang dipengaruhi oleh objek/user

\subsection{METODE EKSPERIMEN}

Untuk membuktikan metode yang diusulkan pada makalah ini, maka penulis melakukan eksperimen pada ruangan / hunian tempat tinggal dengan melakukan dua eksperimen secara berturut-turut.

\section{Pengaturan}

BLE merupakan spesifikasi baru dari Bluetooth yang rendah konsumsi energy dan dapat dikembangkan untuk aplikasi smart home, health, fitness, termasuk positioning. Pada eksperimen ini, penulis menggunakan BLE yang dikembangkan untuk system retail (gambar 2). Percobaan pertama, menentukan area yang digunakan untuk meng capture nilai RSSI dengan 3 Tx dan $1 \mathrm{Rx}$ seperti pada gambar 2. Luas area pada percobaan ini yaitu $3 \times 2,80 \times 2,5 \mathrm{~m}$.

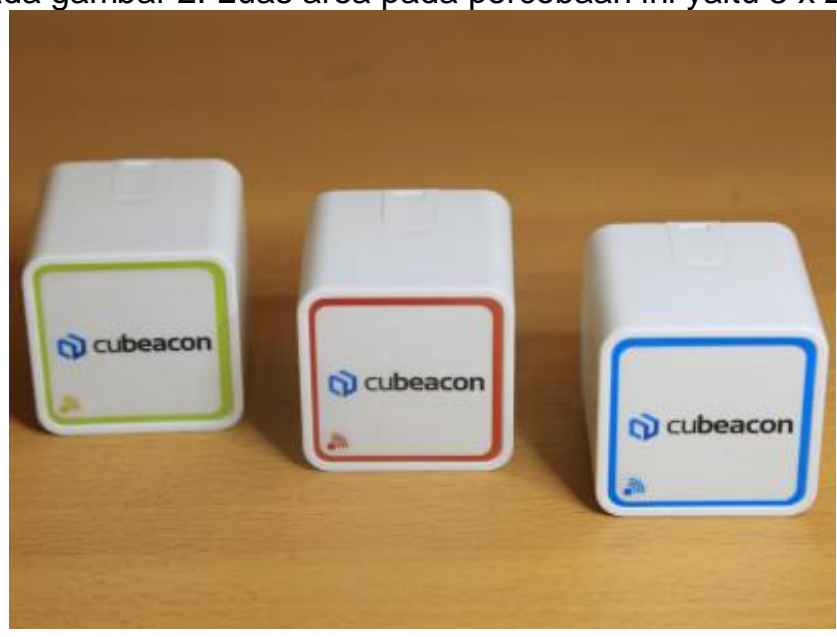

Gambar 2. Perangkat BLE yang digunakan 

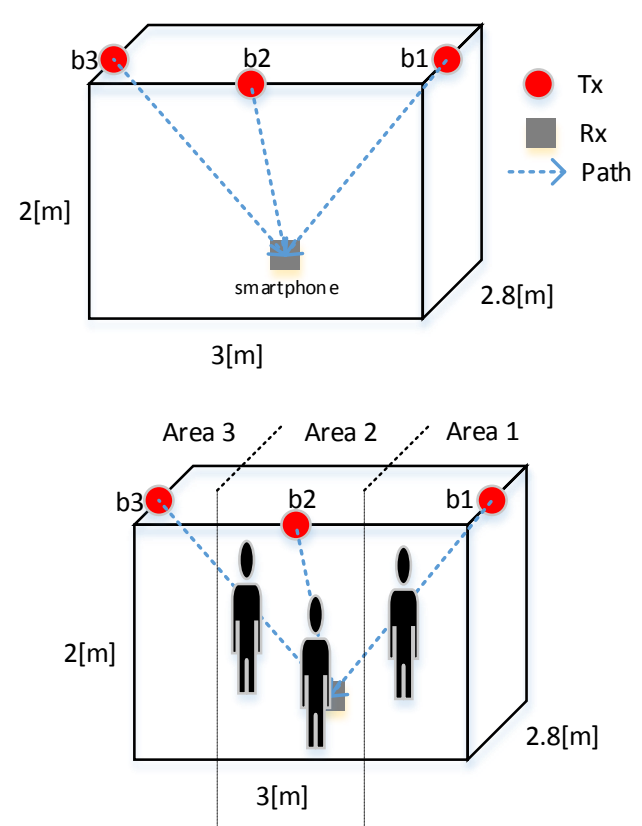

Gambar 3. (a) Skenario percobaan I dengan 3 lokasi Tx dan 1 Rx;(b) Percobaan II dengan adanya human presence

\section{Pemrosesan sinyal RSSI}

RSSI merupakan salah satu parameter yang digunakan untuk mencari jarak atau distance (d) antara transmitter $(T x)$ dengan receiver $(R x)$. RSSI tidak hanya ditemukan pada Bluetooth saja, teknologi WLAN atau Wi-Fi juga mempunyai nilai RSSI saat digunakan untuk keperluan positioning. Nilai RSSI yang diterima oleh antena penerima menunjukkan kuat daya sinyal ( $R x$ power) yang dinyatakan dalam dB (desibel). Untuk membaca nilai RSSI dapat digunakan aplikasi pendukung pihak ketiga yang dikembangkan di system operasi yang berjalan di smartphone

Sistem yang diusulkan pada makalah yaitu untuk mengenali keberadaan object/user (exist/no exist) dan seberapa besar pengaruh yang ditimbulkan pada path yang dilaluinya. Pada gambar 4 merupakan prosedur untuk pemrosesan sinyal RSSI yang diperoleh dari dua percobaan.

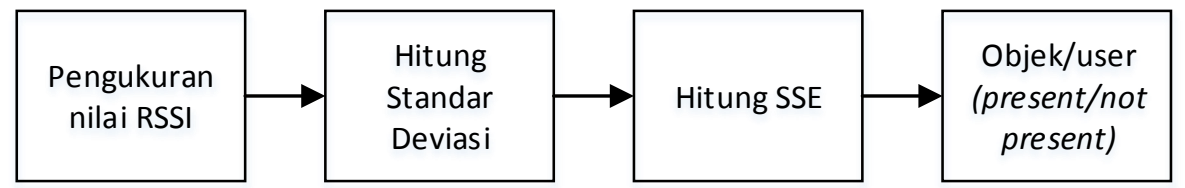

Gambar 4. Prosedur pemrosesan nilai RSSI

$$
\operatorname{SSE}_{i}=\sum_{x=1}^{n}\left(\sigma_{m}^{l}-\sigma_{i, \min (1 \leq x \leq n)}^{m}\right)^{2}
$$

Dimana $i$ merupakan kondisi dari area, dengan $\sigma^{l}$ sebagai standar deviasi dari data dasar untuk path $x$, dan $\sigma^{m}$ sebagai standar deviasi dari data yang diukur untuk path $x$ dibawah kondisi $i$. Perlu dicatat bahwa min dalam persamaan berarti untuk memilih nilai minimum diantara nilai yang ada untuk path yang berbeda. 


\section{HASIL DAN ANALISA}

Gambar 5 menunjukkan hasil pengukuran tiga buah beacon yang terpasang pada kondisi statis. Nilai RSSI dari beacon diambil dari proses bluetooth scanning smartphone yang juga pada posisi statis. Rentang waktu pengambilan RSSI adalah selama 60 detik, dimana beacon mengirimkan nilai RSSI per detik.

Terdapat dua skenario pada pengambilan data, skenario pertama yaitu dengan menempatkan beacon tanpa keberadaan objek (manusia) dan skenario kedua dengan keberadaan objek (manusia). Seperti pada gambar 5, nilai RSSI pada dasarnya stabil ketika tidak ada keberadaan objek manusia, namun ketika terdapat objek maka nilai RSSI dapat bervariasi sehingga mempengaruhi keakuratan. Nilai standar deviasi pada hasil pengukuran ini digunakan sebagai baseline data untuk mengetahui dampak yang ditimbulkan dengan adanya keberadaan objek manusia.

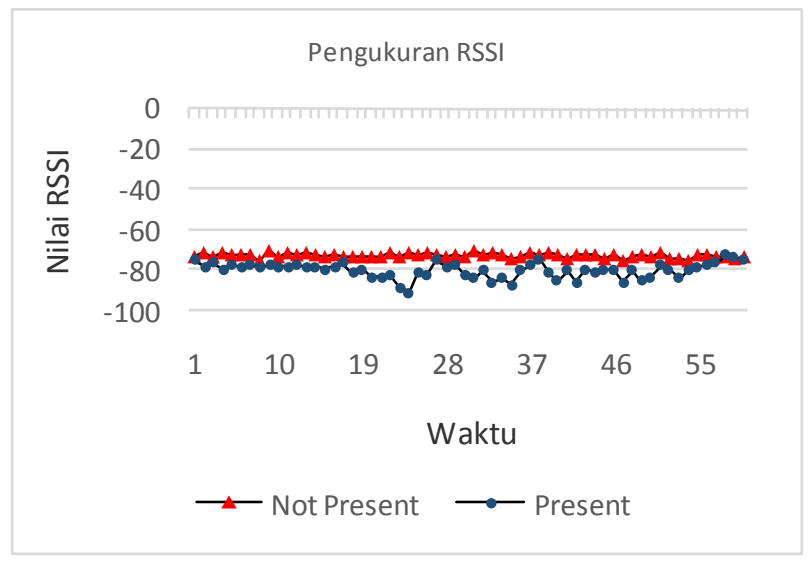

Gambar 5. Hasil pengukuran nilai RSSI pada beacon

Tabel 1 memberikan hasil percobaan untuk kinerja setiap beacon pada setiap kondis $i$ (present/not present). Nilai SSE dihasilkan dari selisih masing-masing standar deviasi beacon pada saat kondisi not present dan present. Dari selisih tersebut dapat diketahui bahwa human presence dapat mempengaruhi sinyal yang diterima sehingga menyebabkan adanya fluktuasi sinyal RSSI. Pada table 2, angka yang dicetak tebal merupakan nilai yang diperoleh ketika objek/pengguna berada tepat di depan beacon, pada scenario no-one rata-rata nilai RSSI yang dihasilkan adalah $-73 \mathrm{dBm}$ dengan jarak terukur $2 \mathrm{~m}$, sedangkan pada kondisi present rata-rata nilai RSSI yang dihasilkan adalah $-85 \mathrm{dBm}$ dengan jarak $3 \mathrm{~m}$. Terdapat selisih jarak $1 \mathrm{~m}$ antara masing-masing beacon ke node (smartphone).

Tabel 1. Hasil perhitungan SSE

\begin{tabular}{cccc}
\hline \multirow{2}{*}{ Beacon } & \multicolumn{2}{c}{ Skenario } & Nilai \\
\cline { 2 - 3 } & Not Present & Present & SSE \\
\hline I & 1,142 & 3,942 & 2,800 \\
II & 0,947 & 3,608 & 3,607 \\
III & 1,006 & 4,515 & 3,509 \\
\hline
\end{tabular}

Tabel 2. Hasil perhitungan untuk setiap kasus keberadaan objek

\begin{tabular}{ccccc}
\hline \multirow{2}{*}{ Case } & Status & \multicolumn{3}{c}{ Area } \\
\cline { 3 - 5 } & Objek & $\mathbf{1}$ & $\mathbf{2}$ & $\mathbf{3}$ \\
\hline I & No-one & 1,142 & 0,947 & 1,006 \\
II & Area 1 & $\mathbf{3 , 4 4 1}$ & 2,179 & 2,246 \\
III & Area 2 & 2,302 & $\mathbf{4 , 0 9 2}$ & 1,768 \\
IV & Area 3 & 2,651 & 1,599 & $\mathbf{2 , 6 6 6}$ \\
V & Area 1/2/3 & $\mathbf{3 , 9 4 2}$ & $\mathbf{3 , 6 0 8}$ & $\mathbf{4 , 5 1 5}$ \\
\hline
\end{tabular}




\section{KESIMPULAN DAN SARAN}

Estimasi posisi objek/pengguna merupakan tujuan penting untuk merealisasikan layanan yang menawarkan keamanan dan keselamatan, khususnya aplikasi yang diperuntukkan bagi manusia lanjut/manula yang berada di rumah ketika menjalani masa perawatan di tempat tinggalnya. Makalah ini mengusulkan metode sederhana dengan menggunakan parameter sinyal RSSI untuk menentukan posisi objek ketika berada di dalam ruangan atau tidak, serta pengaruh seberapa besar error yang dihasilkan oleh adanya human presence ketika berada di lingkungan pengukuran.

Terdapat dua percobaan yang dilakukan untuk menguji kinerja sinyal RSSI. Percobaan pertama dengan kondisi not present menunjukkan kinerja yang baik. Namun, pada percobaan kedua (present) dengan berbagai status objek yang berada di ruangan yang sama, menghasilkan kinerja RSSI yang kurang baik, dimana terdapat pergeseran nilai RSSI pada pengukuran pertama diperoleh rata-rata RSSI $-73 \mathrm{dBm}$ dengan range jarak $2 \mathrm{~m}$, pengukuran kedua diperoleh nilai rata-rata RSSI $-85 \mathrm{dBm}$ dengan range jarak $3 \mathrm{~m}$. Dengan hasil tersebut diatas dapat disimpulkan bahwa human presence dalam area penelitian positioning sangat berpengaruh terhadap kinerja kuat sinyal (RSSI) dan memberikan dampak yang signifikan yaitu pergeseran jarak hingga $1 \mathrm{~m}$.

Pada penelitian mendatang mengevaluasi penempatan beacon untuk meningkatkan akurasi system, karena pada penelitian ini tidak mencantumkan kriteria penempatan beacon.

\section{DAFTAR PUSTAKA}

K. Al Nuaimi and H. Kamel, "A survey of indoor positioning systems and algorithms," 2011 Int. Conf. Innov. Inf. Technol. IIT 2011, pp. 185-190, 2011.

IndoorLBS, "Indoor LBS and Hyper-Local Content is the Next Gold Rush for Mobile Commerce," 2010. [Online]. Available: http://indoorlbs.blogspot.com/2010/06/indoor-lbs-andhyper-local-content-is.html.

B. SIG, "Bluetooth $\AA$ Core Specification 4.2," 2014. [Online]. Available: https://www.bluetooth.org/en-us/specification/adopted-specifications.

H. Liu, H. Darabi, P. Banerjee, and J. Liu, "Survey of Wireless Indoor Positioning Techniques and Systems," IEEE Trans. Syst. Man, Cybern. Part C Appl. Rev., vol. 37, no. 6, pp. 1067-1080, Nov. 2007.

N. Pirzada, M. Y. Nayan, F. Subhan, M. F. Hassan, and M. A. Khan, "Comparative Analysis of Active and Passive Indoor Localization Systems," AASRI Procedia, vol. 5, pp. 9297, 2013.

I. Journal and E. Engineering, "A Survey of Indoor Localization Techniques," IOSR J. Electr. Electron. Eng., vol. 6, no. 3, pp. 69-76, 2013.

Z. Yan, J. Yang, and E. Tapia, "Smartphone bluetooth based social sensing," Proc. 2013 ACM Conf. ..., pp. 95-98, 2013.

M. E. Rida, F. Liu, Y. Jadi, A. A. A. Algawhari, and A. Askourih, "Indoor Location Position Based on Bluetooth Signal Strength," 2015, pp. 769-773. 